\title{
Morbidity and Mortality Indicators in Acute Organophosphate Poisoning in Zagazig University Hospital, Egypt: Retrospective Study
}

\author{
Dalia M. Amin*, Marwa T. Abaza, Doaa Sh. El Azawy, Amany I. Ahmed \\ Forensic Medicine and Clinical Toxicology, Anesthesia \& ICU and Biochemistry, Departments Faculty of Medicine and \\ Veterinary Medicine, Zagazig University, Zagazig, Egypt \\ Email: *daliaamin013@gmail.com
}

How to cite this paper: Amin, D.M., Abaza, M.T., El Azawy, D.S. and Ahmed, A.I. (2018) Morbidity and Mortality Indicators in Acute Organophosphate Poisoning in Zagazig University Hospital, Egypt: Retrospective Study. Occupational Diseases and Environmental Medicine, 6, 130-140. https://doi.org/10.4236/odem.2018.64011

Received: September 10, 2018

Accepted: October 27, 2018

Published: October 30, 2018

Copyright $\odot 2018$ by authors and Scientific Research Publishing Inc. This work is licensed under the Creative Commons Attribution International License (CC BY 4.0).

http://creativecommons.org/licenses/by/4.0/

(c) (i) Open Access

\begin{abstract}
Introduction: Organ phosphorus (OP) toxicity has been studied extensively because of its world wide use. Toxicity of organophosphates is the result of inhibition of acetyl cholinesterase resulting in cholinergic signs. Aim of the Work: To evaluate initial indicators that can indicate prognosis of patients in OP poisoning. Materials and Methods: A retrospective study conducted in Zagazig university hospital over a year. OP poisoning was clinically diagnosed with history of OP compound exposure and confirmed by low pseudo cholinesterase levels. Results: In the present study, 76 patients were enrolled. Major cases were male. High mortality rates were in the youth and in prolonged ventilated patients. The mortality rate was proportionally related to lag time after exposure and plasma pseudo cholinesterase levels. Electrolyte disturbance did not affect clinical outcome. Conclusion: From this study, it could be concluded that mortality is directly proportionate to the lag time, amount of OP consumed, clinical severity, pseudo cholinesterase levels and duration of ventilator support. This study helps in rapid diagnosis, and rapid early and effective treatment, which may result in decreasing the morbidity and mortality rates. Recommendation: It is recommended to increase awareness regarding the rapid diagnosis, and rapid effective treatment of organ phosphorous.
\end{abstract}

\section{Keywords}

Mortality, Organ Phosphorus Compounds, Pseudo Cholinesterase

\section{Introduction}

Developing countries are suffering from organophosphate (OP) poisoning as a 
serious health problem. Many cases of severe poisoning and more than 220,000 deaths recorded every year. The mammalian animals' toxicity is due to widespread use in many purposes as agriculture and veterinary medicine [1].

Exposure to organ phosphorus nerve agents, the most deadly warfare agents are sulphur mustard, Lewisite and nerve agents appear to be the most frequently chemical warfare agents disposed of at the sea. The biomarker detection and identification of exposure are important for the diagnosis and treatment of poisoning, in addition to health monitoring for specific workers [2].

Organophosphate (OP) inhibits the enzyme acetyl cholinesterase increasing acetylcholine in muscarinic and nicotinic receptors in the peripheral and central nervous systems [3].

It causes neurological squeal and has a high mortality rate [4]. Many patients have cardio respiratory arrests after admission, $38 \%$ of patients requiring intubation in a study [5]. The case fatality rate is higher in developing countries compared with developed countries nearly $20 \%$. Numerous indicators have been used for predicting outcome in OP poisoning. Many of these indicators are applicable now [6].

Pradeepkumar et al. (2016) [7] reported that it was possible to predict inpatient mortality in OP poisoning using a scoring system based on simple clinical parameters recorded solely at admission. These systems enable physicians to classify patients at high risk and may dye early, allowing admission in intensive care unit.

The aim of the study is to predict the indicator of the morbidity and mortality in acute organophosphate poisoning in Zagazig University Hospital, Egypt.

\section{Materials and Methods}

\subsection{Study Population}

This retrospective cohort study was conducted on consecutively presented organophosphrus (OP) poisoned patients, admitted in Zagazig University Hospitals from December 2015 to November 2016. Exclusion and inclusion criteria that followed up in our study were: Patients who having diabetes mellitus, thyroid disease, chronic heart diseases and hepatic or renal failure, also patients subjected to cholinergic or sympatholytic drugs or any other medications for chronic disease were excluded. According to these exclusion criteria, only 76 OP-poisoned patients were included in this study. They were presented within 6 $\mathrm{h}$ of OP ingestion or inhalation. The cases were suffering from vomiting, diarrhea, salivation, urination, sweating, secretions, bradycardia, hypotension, miosis, chest crepitation, weakness, fasciculation, cramps, paralysis, coma and respiratory failure and classified clinically by Peradeniya organ phosphorus poisoning (POP) score [8]. Total leucocytes counts and pseudo cholinesterase levels were done to all patient and they are treated according to the standard protocol in the hospital by Decontamination, atropine, obidoxime and mechanical ventilation to the required patients [9]. The necessary permission was taken from the university ethical committee. 


\subsection{Parameters of Evaluation}

Time lagged after ingestion/inhalation to presentation was taken by the history.

The pulse, blood pressure $\mathrm{SpO}_{2}$ at room air and Glasgow Coma Scale (GCS) were detected on examination.

Total leukocyte counts (TLC) (reference range $4000-11,000 / \mathrm{mm}^{3}$ ), pseudo cholinesterase levels (reference range 2000 - $6000 \mathrm{IU} / \mathrm{L}$ ) values were detected as the following.

\subsection{Determination of Serum Pseudo Cholinesterase Level}

Serum pseudo cholinesterase activity was determined calorimetrically as Ellman et al. (1961) method [10]. The Briefly, $4 \mathrm{ml}$ solution containing $4 \mathrm{mM}$ tris buffer of S-butyrylthiocholine iodide (substrate) were pre-incubated at $37^{\circ} \mathrm{C}$ for $10 \mathrm{~min}$ with coupling. $20 \mu \mathrm{l}$ of plasma samples was added. The mixture was vortexed and absorbance of produced yellow colour was read spectrophotometrically at $412 \mathrm{~nm}$. Activity was recorded as U/l.

\subsection{Total Leucocyte Count $\left(\times 10^{3} / \mathrm{mm}^{3}\right)$}

White blood cell count was done by visual method using haemocytometer as described by Wintrobe et al. (1975) [11].

\section{Morbidity indicators:}

The requirement of mechanical ventilator and hospital stay.

Relative risk (RR) of requirement of mechanical ventilation and hospital stay $>7$ days was calculated in patients with:

- pseudo cholinesterase level < (1800 IU/L) and > (1800 IU/L), patients presenting in $<2 \mathrm{~h}$ and $\geq 2 \mathrm{~h}$ after exposure.

- patients with GCS $\leq 12$ and $>12$.

- Patients with $\mathrm{SpO}_{2}<85 \%$ and $\geq 85 \%$ at room air on admission.

Pearson's correlation analysis was done to assess association between hospital stay $>7$ days and requirement of mechanical ventilation with the other clinical parameters.

\subsection{Statistical Analysis}

The collected data were statistically analyzed using SPSS program version 15 . Quantitative data were summarized as mean \pm standard deviation (X $\pm S D$ ). Qualitative data were illustrated as percentage. Test of significance for qualitative data was X2 (chi-square) test. Test of significance for quantitative data was done using student $t$ tests for comparison between group's means.

The correlation between two variables was done by Pearson's correlation analysis. The significance level was considered at $\mathrm{p}$ value $<0.05$.

\section{Results}

The general features of the 76 study subjects with acute OP poisoning on admission, are summarized in (Table 1). The study population included mainly 
Table 1. Basic features of the study population.

\begin{tabular}{cc}
\hline Characteristic & $(\mathrm{X} \pm \mathrm{SD})$ \\
\hline Age (years) & $27.18 \pm 10.29$ \\
$\mathbf{1 5}-\mathbf{2 5}$ & $38(50 \%)$ \\
$\mathbf{2 5}-\mathbf{3 5}$ & $13(16.32 \%)$ \\
$\mathbf{3 5}-\mathbf{4 5}$ & $25(33.68 \%)$ \\
Sex & \\
Males & $46(60.53 \%)$ \\
Females & $30(39.47 \%)$ \\
Serum pseudo cholinesterase (IU/L) & $3383 \pm 2847^{\star}$ \\
Time lag after exposure (h) & $2.63 \pm 2.85$ \\
GCS & $12.3 \pm 3.54$ \\
SpO ${ }_{2}$ in room air (\%) & $91.13 \pm 11.23^{*}$ \\
Ventilation required & $26(34.21 \%)$ \\
Hospital stay (days) & $10.58 \pm 7.35^{\star}$ \\
Mortality & $9(11.53 \%)$ \\
\hline
\end{tabular}

Means \pm Standard Deviation $(\mathrm{X} \pm \mathrm{SD})$. GCS $=$ Glasscow Coma Scale; ${ }^{*}=$ significant; IU/L $=$ international unit/liter; \% = percentage; $\mathrm{h}=$ hour; $\mathrm{SpO}_{2}=$ blood oxygen saturation level.

youth, $65 \%$ of them coming from 15 to 35 years age group (Figure 1). $60 \%$ were males. The ages mean was $27.18 \pm 10.29$ years. The mean hospital stay was 10.5 \pm 7.35 days. $26(34.21 \%)$ patients needed mechanical ventilation. $9(11.53 \%)$ of the 76 patients died all of whom were mechanically ventilated.

The patients that did not required mechanical ventilation showed high GCS score; $\mathrm{SpO}_{2}$ and pseudo cholinesterase levels while the time lagged after exposure and TLC were higher in the ventilated group. Statistically significant difference was observed (between ventilated and nonventilated groups) as that means value of GCS, $\mathrm{SpO}_{2}$, pseudo cholinesterase and were highly increased in the non ventilated group in comparison with the ventilated patients while the time lag after exposure on admission mean value was highly decreased in the non ventilated patients in comparison to the ventilated groups (Table 2), but these groups showed no significant difference in the mean of age or TLC were nearly similar.

The initial parameters were also compared between patients with hospital stay $\leq 7$ days and $>7$ days (Table 3 ). Statistically significant differences were observed in the means of GCS, $\mathrm{SpO}_{2}$, pseudo cholinesterase as that they highly increased in patients with hospital stay less than 7 days in comparison with the patients who stayed more than 7 days in the hospital and time lag after exposure mean value were highly decreased in patients stayed less than 7 days in comparison with that of hospital stay more than 7 days.

The means of GCS, $\mathrm{SpO}_{2}$, pseudo cholinesterase and time lag after exposure on admission showed statistically significant difference as that they highly increased in patients who survived in comparison with the patients who expired and time lag after exposure mean value were highly decreased in patients survived in comparison with that expired (Table 4). 


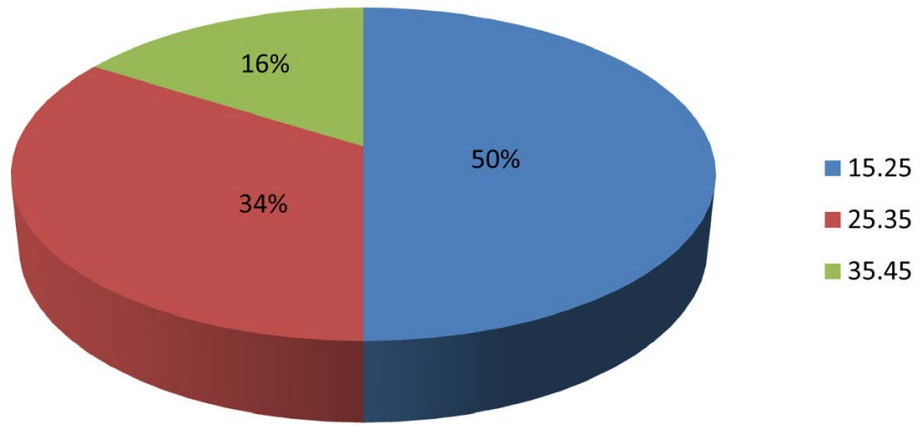

Figure 1. Age distribution between study groups.

Table 2. Comparison of the initial indicators in patients with or without requirement of mechanical ventilation.

\begin{tabular}{cccc}
\hline Indicator & $\begin{array}{c}\text { Required ventilation } \\
\mathbf{N}=\mathbf{2 6}(\mathbf{X} \pm \mathbf{S D})\end{array}$ & $\begin{array}{c}\text { Not ventilated } \\
\mathbf{N}=\mathbf{5 0}(\mathbf{X} \pm \mathbf{S D})\end{array}$ & P value \\
\hline Age & $29 \pm 9.86$ & $29.28 \pm 12.16$ & 0.94 \\
GCS & $9.6 \pm 4.25$ & $14 \pm 2.23$ & $<0.001^{* *}$ \\
TLC & $13000 \pm 7323$ & $9000 \pm 3234$ & 0.079 \\
$\mathrm{SpO}_{2}$ & $81.79 \pm 14.44$ & $96.4 \pm 3.73$ & 0.003 \\
$\begin{array}{c}\text { Pseudocholineesterase level } \\
\text { (IU/L) }\end{array}$ & $795 \pm 676$ & $4678 \pm 2600$ & $<0.001^{* *}$ \\
Time lag after exposure (h) & $5 \pm 3.74$ & $1.41 \pm 0.95$ & $<0.001^{* *}$ \\
\hline
\end{tabular}

$\mathrm{N}=$ number; Means \pm Standard Deviation $(\mathrm{X} \pm \mathrm{SD})$; GCS $=$ Glasscow Coma Scale; TLC $=$ Total Leucocytes Count; $\mathrm{h}=$ hour; $\mathrm{SpO}_{2}=$ blood oxygen saturation level; $\mathrm{IU} / \mathrm{L}=$ international unit/litre; ${ }^{*}$ = highly significant.

Table 3. Comparison of the initial indicators between patients with hospital stay days and $>7$ days.

\begin{tabular}{cccc}
\hline Indicator & $\begin{array}{c}\text { Hospital stay }>7 \text { days } \\
(\mathbf{1 0 . 5 8} \pm \mathbf{7 . 3 5}) \\
(\mathrm{X} \pm \mathrm{SD})\end{array}$ & $\begin{array}{c}\text { Hospital stay days } \\
(\mathbf{4 . 0 2} \pm \mathbf{3 . 2 1}) \\
(\mathrm{X} \pm \mathrm{SD})\end{array}$ & P value \\
\hline Age & $30.92 \pm 12.7$ & $27.43 \pm 10.13$ & 0.36 \\
GCS & $9.41 \pm 4.39$ & $14.17 \pm 1.94$ & $<0.001^{\star *}$ \\
TLC & $11318 \pm 6497$ & $10204 \pm 4425$ & 0.56 \\
SpO 2 & $81.64 \pm 13.87$ & $97 \pm 1.56$ & $<0.001^{* *}$ \\
$\begin{array}{c}\text { Pseudocholineesterase level } \\
\text { (IU/L) }\end{array}$ & $1122 \pm 1230$ & $4874 \pm 2618$ & $<0.001^{* *}$ \\
Time lag after exposure (h) & $4.48 \pm 3.87$ & $1.43 \pm 0.99$ & $<0.001^{* *}$ \\
\hline
\end{tabular}

Means \pm Standard Deviation $(\mathrm{X} \pm \mathrm{SD})$. GCS $=$ Glasscow Coma Scale; TLC $=$ Total Leucocytes Count; $\mathrm{h}=$ hour; $\mathrm{SpO}_{2}=$ blood oxygen saturation level; IU/L = international unit/litre. ${ }^{* *}=$ highly significant.

A moderate negative correlation was seen between (pseudo cholinesterase level and GCS) with the hospital stay as the hospital stay increase these value decreased (Table 5). 
Table 4. Comparison of the initial indicators between patients who survived and expired.

\begin{tabular}{cccc}
\hline Parameter & $\begin{array}{c}\text { Expired } \\
\mathbf{N}=\mathbf{9}(\mathrm{X} \pm \mathrm{SD})\end{array}$ & $\begin{array}{c}\text { Survived } \\
\mathbf{N}=\mathbf{6 7}(\mathrm{X} \pm \mathrm{SD})\end{array}$ & P value \\
\hline Age & $34.25 \pm 10.9$ & $28.58 \pm 11.134$ & 0.32 \\
GCS & $6.75 \pm 5.56$ & $13.17 \pm 2.81$ & $<0.001^{\star *}$ \\
TLC & $10950 \pm 6786$ & $10607 \pm 5206$ & 0.92 \\
$\mathrm{SpO}_{2}$ & $77.25 \pm 14.5$ & $92.76 \pm 9.81$ & $<0.001^{\star *}$ \\
$\begin{array}{c}\text { Pseudocholineesterase level } \\
\text { (IU/L) }\end{array}$ & $507 \pm 15$ & $3722 \pm 2823$ & $<0.001^{\star *}$ \\
Time lag after exposure (h) & $9.25 \pm 4.27$ & $1.86 \pm 1.23$ & $<0.001^{\star *}$ \\
\hline
\end{tabular}

$\mathrm{N}=$ number. Means \pm Standard Deviation $(\mathrm{X} \pm \mathrm{SD})$; GCS = Glasscow Coma Scale. TLC = Total Leucocytes Count; $\mathrm{h}=$ hour; $\mathrm{SpO}_{2}=$ blood oxygen saturation level. IU/L $=$ international unit/litre. ${ }^{* *}=$ highly significant.

Table 5. Correlation between hospital stay and pseudo cholinesterase level \& GCS.

\begin{tabular}{ccc}
\hline & Hospital stay & \\
\hline Parameter & $\mathbf{r}$ & P \\
\hline Pseudo cholinesterase level IU/L & -0.59 & $<0.05^{\star}$ \\
GCS & -0.53 & $0.005^{*}$ \\
\hline
\end{tabular}

* = significant; GCS = Glasscow coma scale IU/L = international unit/litre.

Significant association was observed between mortality as that increase in the mortality rate associated with pseudo cholinesterase $<1800, \mathrm{SpO}_{2}<85 \%$, GCS $\leq$ 12 and time lag after exposure on admission $\geq 2 \mathrm{~h}$ (Table 6).

Statistically significant association was found between requirement of mechanical ventilation as that increase in the application of mechanical ventilation associated with pseudo cholinesterase $<1800$, time lag after exposure on admission $\geq 2 \mathrm{~h}, \mathrm{SpO}_{2}$ (at room air) $<85 \%$ and GCS $\leq 12$ (Table 7).

Statistically significant association was found between hospital stay $>7$ days as that the more the days stayed by the patients in the hospital increased with pseudo cholinesterase $<1800$ and GCS $\leq 12$ \{(RR: 6.28; 95\% CI: $5.74-13.19$ ) and (RR: 4.9)\} respectively. There was a mild association between hospital stay $>7$ days mildly associated with $\mathrm{SpO}_{2}$ (at room air) on admission $<85 \%$ ) and time lag after exposure on admission $\geq 2 \mathrm{~h}$ (Table 8).

\section{Discussion}

Organophosphate poisoning is fatal and causes high mortality and morbidity. In this study, the mortality was $11.53 \%$ (9 deaths in 76 patients), and 26 (34.21\%) patients supported by mechanical ventilator. These results are in accordance with John et al. (2004) [12] who estimated that death rate from OP ingestion ranges from $15 \%$ to $25 \%$.

In our study, we selected only age, time lag after exposure, GCS, $\mathrm{SpO}_{2}$ at room air, TLC and initial pseudo cholinesterase to assess the association with requirement of ventilation or hospital stay. We did not select the respiratory rate as 
Table 6. Association between mortality and other parameters.

\begin{tabular}{ccc}
\hline \multicolumn{2}{c}{ Mortality } \\
\hline Parameter & \multicolumn{2}{c}{ RR 95\% CI } \\
\hline Pseudo cholinesterase $<1800 \mathrm{IU} / \mathrm{L}$ & 6.76 & $2.25-26.60$ \\
$\mathrm{SpO}_{2}<85 \%$ & 11.27 & $2.50-50.33$ \\
GCS $\leq 12$ & 9.4 & $1.84-38.27$ \\
Time lag after exposure on admission $\geq 2 \mathrm{~h}$ & 15.52 & $2.6-98.02$ \\
\hline
\end{tabular}

$\mathrm{RR}=$ Relative Risk; $\mathrm{CI}=$ confidence Interval.

Table 7. Association between requirement of mechanical ventilation and other parameters.

\begin{tabular}{ccc}
\hline \multicolumn{2}{c}{ Requirement of mechanical ventilation } \\
\hline Parameter & RR 95\% CI \\
\hline Pseudo cholinesterase $<1800 \mathrm{IU} / \mathrm{L}$ & 11.57 & $7.07-37.46$ \\
$\mathrm{SpO}_{2}<85 \%$ & 4.37 & $2.57-7.49$ \\
GCS $\leq 12$ & 4.78 & $2.14-6.59$ \\
Time lag after exposure on admission $\geq 2 \mathrm{~h}$ & 13.95 & $3.04-49.25$ \\
\hline
\end{tabular}

$\mathrm{RR}=$ Relative Risk; $\mathrm{CI}=$ confidence Interval; $\mathrm{GCS}=$ Glasscow Coma Scale; $\mathrm{H}=$ hour; $\mathrm{SpO}_{2}=$ blood oxygen saturation level. IU/L = international unit/litre.

Table 8. Association between hospital stay $>7$ days and other parameters.

\begin{tabular}{ccc}
\hline \multicolumn{2}{c}{ Hospital stay $>7$ days } \\
\hline Parameter & RR 95\% CI \\
\hline Pseudo cholinesterase $<1800 \mathrm{IU} / \mathrm{L}$ & 6.28 & $5.74-13.19$ \\
$\mathrm{SpO}_{2}<85 \%$ & 3.28 & $1.71-6.27$ \\
$\mathrm{GCS} \leq 12$ & 4.9 & $1.74-6.59$ \\
Time lag after exposure on admission $\geq 2 \mathrm{~h}$ & 2.75 & $1.40-5.38$ \\
\hline
\end{tabular}

$\mathrm{RR}=$ Relative Risk; $\mathrm{CI}=$ confidence Interval; $\mathrm{h}=$ hour; $\mathrm{SpO}_{2}=$ blood oxygen saturation level; $\mathrm{IU} / \mathrm{L}=$ international unit/litre.

severe OP poisoning can cause central respiratory inhibition or stimulation leading to reduced respiratory rate or increased respiratory rate. It would not be a reliable guide to severity. Also OP amount ingested is not practical, most of the data given by the patient or the relative about the amount left in the bottle [13]. The respiratory rate or amount ingested was not included into our analysis.

It was difficult to use pupil size and heart rate during clinical evaluation as parameters in our analysis because of frequent use of atropine before hospital presentation. Using cyanosis as a parameter was difficult as it is subjective [14] or arterial blood gas readings, are misleading because of amount of inspired oxygen was not evaluated. So, oxygen saturation at room air on admission was only included for analysis. Katz and Brooks (2015) [15] showed that outcome varies according to the certain OP compound consumed; also the proper identification of the specific OP compound ingested in many cases was difficult so, a 
compound-based analysis could not be done.

Lee and Tai (2001) [16] identified morbidity and mortality predictors in OP poisoning by an Acute Physiology and Chronic Health Evaluation II (APACHE II) score $>26$ was reported to be a poor prognosis while Eizadi-Mood et al. (2007) [17] and Costa et al. (2015) [18] reported that both APACHE II score and GCS $<13$ predicted poor outcome.

A study by Goswamy et al. (1994) [19] stated that pseudo cholinesterase level is useful in predicting the prognosis in OP poisoning. However, Aygun et al. (2002) [20] have reported that low levels of pseudo cholinesterase support the diagnosis of acute OP poisoning, but were not related to clinical severity.

In Indian study by Rehiman et al. (2008) [21] declared that the Peradenya organ phosphorus poisoning scale and pseudo cholinesterase level on admission and days of hospital stay were useful to assess the severity of cases in parallel with our results.

Sam et al. (2009) [22] assessed the practical indices such as GCS, APACHE II and mortality rate (MR) can be applied in predicting mortality in OP poisoning

It was reported that serum creatinine phosphokinase level, true cholinesterase level, $\mathrm{PH}$ of the blood and amount of atropine given were strongly related with clinical severity of OP poisoning [23].

Sanjay et al. (2017) [24] reported association of low pseudo cholinesterase levels with severity, but the parameters as APACHE II and MR were not applicable and lengthy.

Tang et al. (2016) [25] observed that values between 870 - 1200 on day 1 were associated with prolonged ventilation and higher mortality. Our study confirms this finding. Other parameters used in our study were simple, recorded bedside and rapidly. Although a relation between delayed treatment, hypoxia, and low GCS as shown in our study are predicted.

\section{Conclusion}

We conclude that pseudo cholinesterase $<1800, \mathrm{SpO}_{2}<85 \%$ at room air, GCS $\leq$ 12 and time elapsed after exposure before treatment $\geq 2 \mathrm{~h}$ are the parameters which have a strong association with morbidity and used to develop a severity scoring system in acute OP poisoning cases. This will help in classifying the patient with higher morbidity and help decision-making regarding admission to ICU, referral to more qualified center like rural or remote areas and developing countries with limited resources and to improve outcome.

\section{The Limitations of the Study}

This study was limited to that number of patients and further study on larger population, wider scope and longer duration should be done in the future.

\section{Acknowledgements}

The authors gratefully acknowledge the support and help provided by all the 
staff of Department of Internal Medicine, Department of Anaesthesiology and Intensive Care Unit, Zagazig University Hospitals.

\section{Recommendations}

Generalization of severity scoring system in acute OP poisoning cases including these initial parameters to predict morbidity and mortality of these cases helps health officers in decision-making.

\section{Funding}

This study was not funded by any organization.

\section{Conflicts of Interest}

There is no conflict of interest.

\section{References}

[1] Hung, D.-Z., Yang, H.-J., Li, Y.-F., Lin, C.-L., Chang, S., Sung, F.-C. and Tai, S.C.W. (2015) The Long-Term Effects of Organophosphates Poisoning as a Risk Factor of CVDs: A Nationwide Population-Based Cohort Study. BMJ, 10, 137-140.

[2] Vucinic, S., Antonijevic, B., Tsatsakis, A.M., Vassilopoulou, L., Docea, A.O., Nosyrev, A.E., Izotov, B.N., Thiermann, H., Drakoulis, N. and Brkic, D. (2017) Environmental Exposure to Organophosphorus Nerve Agents. Archives of Toxicology, 56, 163-171.

[3] Lee, S. and Barron, M. (2016) Mechanism-Based Analysis of Acetylcholinesterase Inhibitory Potency of Organophosphates, Carbamates, and Their Analogs. 17 th International Conference on QSAR in Environmental and Health Sciences, Miami Beach, FL, 13-17 June 2016.

https://cfpub.epa.gov/si/si_public_record_report.cfm?dirEntryId=321691

[4] John, V.P., Thomas, I.S. and John, L.M. (2014) Clinical Features of Organophosphate Poisoning: A Review of Different Classification Systems and Approaches. Indian Journal of Critical Care Medicine, 18, 735-745.

[5] Coskun, R., Gundogan, K. and Sezgin, G.C.A. (2015) Retrospective Review of Intensive Care Management of Organophosphate Insecticide Poisoning: Single Center Experience. Archives of Internal Medicine, 18, 644-650.

[6] Eddleston, M. and Phillips, M.R. (2004) Self Poisoning with Pesticides. BMJ, 328, 42-44. https://doi.org/10.1136/bmj.328.7430.42

[7] Pradeepkumar, H., Pradeep, R., Ipe, J. and Karthik, R. (2016) Pseudocholinesterase as a Predictor of Mortality and Morbidity in Organophosphorus Poisoning. Indian Journal of Critical Care Medicine, 20, 601-604. https://doi.org/10.4103/0972-5229.192052

[8] Senanayake, N., Silva, H.J. and Karalliedde, L.A. (1993) Scale to Assess Severity in Organophosphorus Intoxication: POP Scale. Human \& Experimental Toxicology, 12, 297-299. https://doi.org/10.1177/096032719301200407

[9] Ponte, J. (1990) Assisted Ventilation. 2. Indications for Mechanical Ventilation. Thora, 45, 885-890. https://doi.org/10.1136/thx.45.11.885

[10] Ellman, G.L., Courtney, K.D., Andres, V. and Featherstone, R.M. (1961) A New and Rapid Colorimetric Determination of Acetylcholinesterase Activity. Biochemical 
Pharmacology, 7, 90-95. https://doi.org/10.1016/0006-2952(61)90145-9

[11] Wintrobe, M.M., Goodman, L.F. and Dameshet, W. (1975) Red and Blood Cells Counts Using Hemocytometer. American Physical Society, 117, 10-15.

[12] John, F., Sanjay, A., Siddheshwar, V. and Sheshrao, S. (2004) Original Research Article. The Clinico-Demographic Study of Morbidity and Mortality in Patients with Organophosphate Compound Poisoning at Tertiary Care Hospital in Rural India. International Journal of Advances in Medicine, 4, 809-818.

[13] King, M., Aaron, H. and Cynthia, K. (2015) Organophosphate and Carbamate Poisoning. Emergency Medicine Clinics of North America, 33, 133-151. https://doi.org/10.1016/j.emc.2014.09.010

[14] Peter, J.V., Sudarsan, T.I. and Moran, J.L. (2014) Clinical Features of Organophosphate Poisoning: A Review of Different Classification Systems and Approaches. Indian Journal of Critical Care Medicine, 18, 735-745. https://doi.org/10.4103/0972-5229.144017

[15] Katz, K.D. and Brooks, D.E. (2015) Organophosphate Toxicity Workup. Archived 2015-02-09 at the Wayback Machine, "MedScape".

[16] Lee, P. and Tai, D.Y. (2001) Clinical Features of Patients with Acute Organophosphate Poisoning Requiring Intensive Care. Intensive Care Medicine, 27, 694-699. https://doi.org/10.1007/s001340100895

[17] Eizadi-Mood, N., Saghaei, M. and Jabalameli, M. (2007) Predicting Outcomes in Organophosphate Poisoning Based on APACHE II and Modified APACHE II Scores. Human \& Experimental Toxicology, 26, 573-578. https://doi.org/10.1177/09603271060080076

[18] Costa, L., Cole, T., Vitalone, A. and Furlong, C. (2015) Measurement of Paraoxonase (PON1) Status as a Potential Biomarker of Susceptibility to Organophosphate Toxicity. Clinica Chimica Acta, 352, 37-47. https://doi.org/10.1016/j.cccn.2004.09.019

[19] Goswamy, R., Chaudhuri, A. and Mahashur, A.A. (1994) Study of Respiratory Failure in Organophosphate and Carbamate Poisoning. Heart \& Lung, 23, 466-472.

[20] Aygun, D., Doganay, Z., Altintop, L., Guven, H., Onar, M. and Deniz, T. (2002) Serum Acetylcholinesterase and Prognosis of Acute Organophosphate Poisoning. Journal of Clinical Toxicology, 40, 903-910.

[21] Rehiman, S., Lohani, S.P. and Bhattarai, M.C. (2008) Correlation of Serum Cholinesterase Level, Clinical Score at Presentation and Severity of Organophosphorous Poisoning. Journal of Nepal Medical Association, 47, 47-52. https://doi.org/10.31729/jnma.306

[22] Sam, K.G., Kondabolu, K., Pati, D., Kamath, A., Pradeep Kumar, G. and Rao, P. (2009) Poisoning Severity Score, APACHE II and GCS: Effective Clinical Indices for Estimating Severity and Predicting Outcome of Acute Organophosphorus and Carbamate Poisoning. Journal of Forensic and Legal Medicine, 16, 239-247. https://doi.org/10.1016/j.jflm.2008.12.004

[23] Bhattacharyya, K., Phaujdar, S., Sarkar, R. and Mullick, O.S. (2011) Serum Creatine Phosphokinase: A Probable Marker of Severity in Organophosphorus Poisoning. Toxicology International, 18, 117-123. https://doi.org/10.4103/0971-6580.84263

[24] Sanjay, A., Siddheshwar, V. and Sheshrao, S. (2017) The Clinico-Demographic Study of Morbidity and Mortality in Patients with Organophosphate Compound Poisoning at Tertiary Care Hospital in Rural India. International Journal of Advances in Medicine, 4, 809-818. https://doi.org/10.18203/2349-3933.ijam20172277 
[25] Tang, W., Ruan, F., Chen, Q., Chen, S., Shao, X., Gao, J. and Zhang, M. (2016) Independent Prognostic Factors for Acute Organophosphorus Pesticide Poisoning. Respiratory Care, 61, 965-970. https://doi.org/10.4187/respcare.04514 